Bảng 3.3 chỉ ra mối tương quan giữa tỷ lê trầm cảm và một số yếu tố liên quan. Trong đó những bệnh nhân đã điều trị IUI,IVF thất bại trước đó, thời gian điêu trị hố trợ sinh sản trên trên 3 năm, tuổi điều trị trên 37 tuổi có tỷ lê trầm cảm cao hơn và bệnh nhân đã có con trước đó, nguyên nhân vô sinh do chồng có tỷ lệ trầm cảm thấp hơn có ý nghĩa thống kê.

Một số nghiên cứu trên thế giới cũng đưa ra kết luận tương tự, cụ thể trong nghiên cứu của Mariko Ogawa (2011) cho thấy những người phụ nữ điều trị hỗ trợ sinh sản tuổi càng cao và nhiều lần thất bại trước đó có điểm số trầm cảm cao hơn, những phụ nữ biết nguyên nhân vô sinh do chồng có thang điểm trầm cảm thấp hơn nhóm còn lai [7]. Nghiên cứu kinh điển của D. Domar năm 1992 cho rằng phụ nữ điều trị vô sinh 2-3 năm có điểm số trầm cảm cao nhất và giảm dần sau năm thứ 6 [6]. Tuy nhiên trong nghiên cứu của H.Volgsten (2008) cho thây tuổi, thời gian vô sinh, nguyên nhân vô sinh, số lượng chu kì IVF không liên quan đến rối loạn tâm thần nào [8]

Mặc dù chúng tôi không nhận thây mối liên quan giữa trầm cảm và các yếu tố tiên sử xảy thai, phá thai, chồng đi làm xa nhưng một số nghiên cứu tổng quan nhận thấy có sự liên quan giữa các yếu tố này [9]. Điều này gợi ý cần các nghiên cứu sâu hơn nữa để tìm hiểu các yếu tố liên quan đến các yếu tố rối loạn trầm cảm.

\section{KẾT LUÂ̂N}

- Tiền sử thất bại IUI,IVF, tuổi $\geq 37$, thời gian điều trị hố trợ sinh sản trên 3 năm là các yếu tố nguy cơ của rối loạn trầm cảm ở phụ nữ điều trị IVF.

- Nguyên nhân vô sinh do chồng, đã có con trước đó là yếu tố bảo vệ bệnh nhân điều trị IVF khỏi rối loạn trầm cảm.

- Không thấy có mối liên quan giữa các yếu tố khác như tiền sử sảy thai, phá thai, chồng đi làm xa với rối loạn trầm cảm.

\section{TÀI LIÊU THAM KHẢO}

1. Casilla-Lennon M.M., Meltzer-Brody S., và Steiner A.Z. (2016). The effect of antidepressants on fertility. Am J Obstet Gynecol, 215(3), 314.e1-5.

2. Ombelet W., Cooke I., Dyer S. và cộng sự. (2008). Infertility and the provision of infertility medical services in developing countries. Human Reproduction Update, 14(6), 605-621.

3. The importance of $\mathbf{3}$ full cycles of IVF | Blog I News. NICE, <https://www.nice.org.uk/ news/blog/the-importance-of-3-full-cycles-of-ivf $>$, accessed: 13/06/2021.

4. Wu G., Yin T., Yang J. và cộng sự. (2014), Depression and coping strategies of Chinese women undergoing in-vitro fertilization. Eur J Obstet Gynecol Reprod Biol, 183, 155-158.

5. Kiani Z., Simbar M., Hajian S. và cộng sự. (2021). The prevalence of depression symptoms among infertile women: a systematic review and meta-analysis. Fertility Research and Practice, 7(1), 6.

6. Domar A.D., Broome A., Zuttermeister P.C. và cộng sự. (1992). The prevalence and predictability of depression in infertile women. Fertil Steril, 58(6), 1158-1163.

7. Ogawa M., Takamatsu K., và Horiguchi F. (2011). Evaluation of factors associated with the anxiety and depression of female infertility patients. BioPsychoSocial Medicine, 5(1), 15.

8. Volgsten H., Skoog Svanberg A., Ekselius L. và công sứ . (2008). Prevalence of psychiatric disorders in infertile women and men undergoing in vitro fertilization treatment. Hum Reprod, $\mathbf{2 3 ( 9 )}$, 2056-2063.

9. Matsubayashi H., Hosaka T., Izumi S. và cộng sứ. (2004). Increased depression and anxiety in infertile Japanese women resulting from lack of husband's support and feelings of stress. Gen Hosp Psychiatry, 26(5), 398-404.

\title{
KẾT QUẢ BƯớC ĐẦU ĐIỀU TRI NỐT DI CĂN PHỔI BẰNG ĐỐT NHIÊTT SÓNG CAO TẦN
}

\begin{tabular}{|c|c|}
\hline & $\begin{array}{l}\text { Lê Thanh Dũng }{ }^{1} \text {, Vũ Tiến Thế } \\
\text { í Hoài Linh }{ }^{1} \text {, Đào Xuân Hải }{ }^{1} \text {, Thân Văn Sỹ }\end{array}$ \\
\hline $\begin{array}{l}\text { TÓM TẮT. } \\
\text { Mưc tiêu: Đánh giá hiệu quả của phương pháp } \\
\text { đốt nhieệt sóng cao tần (DNSCT) trong điêu trị nốt di }\end{array}$ & 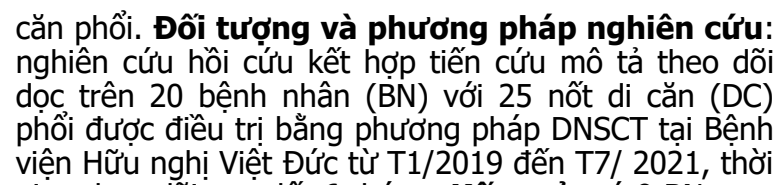 \\
\hline 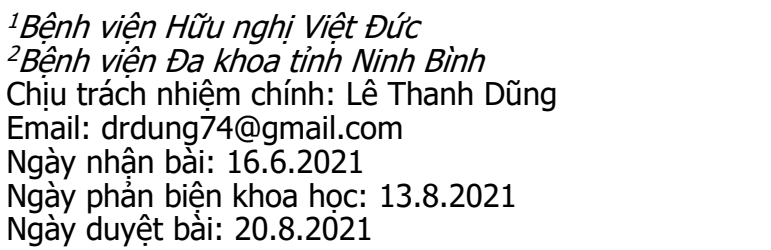 & 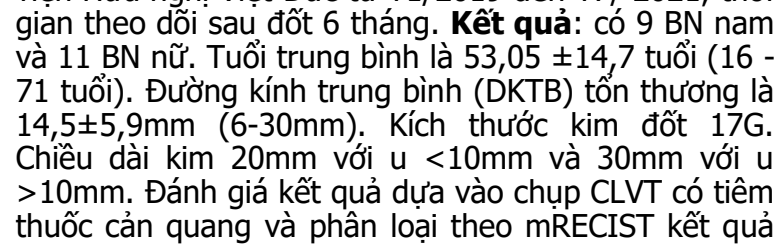 \\
\hline
\end{tabular}


là: $92 \%$ hoai tử hoàn toàn, $8 \%$ hoai tử môt phần. Các biến chứng sau điều trị gồm: sốt $69 \%$, đau ngực $73 \%$, khó thở $15,4 \%$, ho máu số lương ít $11 \%$, tràn khí mức độ ít $11 \%$, viêm thành ngực $3,8 \%$ và tràn dịch màng phổi số lượng ít 3,8\%, không có bênh nhân tử vong. Kết luận: DNSCT là phương pháp an toàn và hiệu quả trong điều tri nốt di căn phổi kích thước $\leq 30 \mathrm{~mm}$ với tỷ lệ đáp ứng hoàn toàn tổn thương cao, tai biến và biến chứng thấp.

Tư khóa: đốt nhiêt sóng cao tần, nốt di căn phổi.

Chữ viêt tắt: cắt lớp vi tính (CLVT), đốt nhiệt sóng cao tần (DNSCT), di căn (DC), đường kính trung bình (DKTB)

\section{SUMMARY \\ INITIAL RESULTS OF RADIOFREQUENCY ABLATION IN THE TREATMENT OF PULMONARY METASTASES}

Purpose: To evaluate the effectiveness of radiofrequency ablation (RFA) in the treatment of pulmonary metastases. Materials and methods: a non-randomized controlled study on 20 patients with 25 lung metastases treated with RFA at Viet Duc Friendship Hospital from January 2019 to July 2021 with follow-up period within 6 months after treatment. Results: There were 9 men and 11 women (mean age of $53.05 \pm 14.7$; range, $16-71$ ). The mean diameter of the lesions was $14.5 \pm 5.9 \mathrm{~mm}$ (range, 630 ). RFA was performed with thermal electrode (17G, $3 \mathrm{~cm}$ tip) with the length of $20 \mathrm{~mm}$ for lesions under $10 \mathrm{~mm}$ or $30 \mathrm{~mm}$ for lesions over $10 \mathrm{~mm}$. The tumor response was evaluated based on mRECIST with $92 \%$ complete necrosis, $8 \%$ partial necrosis. Complications after treatment included fever $(69 \%)$, chest pain $(73 \%)$, dyspnea $(15.4 \%)$, mild hemoptysis $(11 \%)$, mild pneumothorax $(11 \%)$, chest wall inflammation $(3.8 \%)$ and mild effusion (3.8\%). Conclusion: RFA is a safe and effective method for the treatment of pulmonary metastases with a high complete response and a low complication rate.

Keywords. radiofrequency ablation, lung metastasis.

\section{I. ĐẶT VẤN ĐỀ}

Tổn thương di căn phổi thường có tiên lượng kém, điều trị hóa trị liệu toàn thân và điều trị đích là các phương pháp điều trị kinh điển đặc biệt với các loại ung thư di căn nhậy cảm với điểu trị hóa chất, tuy nhiên phần lớn các khối u đặc thường khó đạt được kết quả điêuu trị triệt cắn, hiện nay chiến lược điều trị các khối u di căn còn khu trú có nhiều thay đổi, sử dụng các phương pháp điều trị tại chỗ như phấu thuật, xa trị và đốt nhiệt tại chố đang được nghiên cứu với hiệu quả bước đầu khả quan, trong đó DNSCT là phương pháp phá hủy u tại chố bằng nhiệt, là phương pháp ít xâm lấn cho hiệu quả điều trị triệt căn với các nốt tổn thương di căn có đường kính $\leq 3 \mathrm{~cm}$ với tỷ lê phá huỷ hoàn toàn khối u cao, bảo tồn được phần nhu mô lành, tỷ lệ biến chứng và tử vong thấp.
Tại Việt Nam, hiện chưa có báo cáo nào về tính an toàn, hiệu quả của DNSCT nốt di căn phổi. Vì vậy, chúng tôi tiến hành nghiên cứu: "Kết quả bước đầu điều trị nốt di căn ở phổi băng đốt nhiệt sóng cao tần" với mục tiêu đánh giá tính an toàn và hiệu quả của phương pháp này trong điều trị các nốt di căn phổi.

\section{II. ĐỐI TƯỢNG VÀ PHƯƠNG PHÁP NGHIÊN CỨU}

1. Đối tượng nghiên cứu. 20 bệnh nhân với 25 nốt di căn phổi đã được điều trị bằng DNSCT tại Bệnh viện Hữu nghị Việt Đức, trong thời gian từ T1/2019 đến T7/2021.

Tiêu chuẩn lưa chọn: bệnh nhân có nốt DC phổi trên kết quả giải phẫu bệnh sau sinh thiết hoặc kết quả PET/CT nốt tổn thương tăng chuyển hóa với SUVmax >3 hoặc theo dõi sự phát triển của u lớn hơn $25 \%$ thể tích trong 3 tháng. Tổn thương cách xa mạch máu lớn, khí quản, thực quản và tim $\geq 10 \mathrm{~mm}$, số lượng $\leq 03$ nốt, kích thước nốt $\leq 30 \mathrm{~mm}$, bệnh nhân được giải thích về phương pháp điều trị và đồng ý tham gia nghiên cứu và có hồ sơ lưu trữ đầy đủ.

\section{Phương pháp nghiên cứu}

Phương pháp nghiên cứu: hồi cứu kết hợp tiến cứu mô tả theo dõi dọc.

\section{Phương tiện nghiên cứu:}

- Máy đốt nhiêt sóng cao tần VIVA RF STYTEM (Starmed, south Korea): loại kim 17G điều chỉnh được chiều dài đầu đốt, sử dụng chiều dài đầu đốt $20 \mathrm{~mm}$ với u có $D K T B<10 \mathrm{~mm}$, chiều dài kim $30 \mathrm{~mm}$ với u có DKTB $>10 \mathrm{~mm}$. Công suất tối đa 200W, thời gian đốt tối đa 15 phút.

- Máy CLVT 16 dãy (Siemens, Germany) có phần mềm Fluorocospy: định vị tổn thương theo thời gian thực và theo dõi u trong quá trình can thiệp.

- Quy trình DNSCT nốt di căn phổi tại: Bệnh nhân được nằm ngửa trên bàn chụp, định vị tổn thương trên CLVT, tiến hành sát khuẩn, gây tê tại chổ bằng Lidocain $2 \%$, tiến hành định vị và đưa kim đốt vào khối u dưới hướng dẫn của CLVT có sử dụng Fluoroscopy. Tiến hành đốt tổn thương và theo dõi trong quá trình đốt bằng Fluoroscopy trong quá trình đốt. Tiêu chuẩn xác địch khối u hoại tử hoàn toàn là phần kính mờ sau khi đốt bao quanh $u \geq 5 \mathrm{~mm}$. Tiến hành đốt đường chọc kim để hạn chế di căn theo đường chọc.

Theo dõi và đánh giá sau điều trị: Bệnh nhân được chụp CLVT lồng ngực có tiêm thuốc cản quang sau đốt 1 tháng, 3 tháng. Hoại tử hoàn toàn là phần tổn thương không ngấm thuốc sau tiêm (đông đặc, rải xẹp phổi, dạng ổ dịch) hoặc tổn thương biến mất hoàn toàn. Hoại tử không 
hoàn toàn khi có phần tổ chức u còn ngấm thuốc (trên 15HU).

- Đánh giá đáp ứng tổn thương sau điêu trị theo mRECIST: đáp ứng hoàn toàn, đáp ứng một phần, bệnh ổn đinh và bênh tiến triển.

Xử lý và phân tích số liệu: bằng phân mềm SPSS 20.0.

\section{KẾT QUẢ NGHIÊN CỨU}

Trong thời gian từ 1/2019 đến 7/2021, 20 BN với 25 nốt tổn thương thỏa mãn tiêu chuẩn nghiên cứu đã được điều trị DNSCT

- Độ tuổi trung bình trong nhóm nghiên cứu là 53,05 $\pm 14,7$ tuổi (tuổi thấp nhất 16 , cao nhất 71tuối). Có 9 nam/11 nữ, tỷ lệ nam/nữ: 0,82.

- 7/20 BN di căn từ ung thư biểu mô tế bào gan, $7 / 20 \mathrm{BN}$ di căn từ ung thư đại tràng và $6 / 20$ $\mathrm{BN}$ di căn từ u nguyên bào nuôi. $15 / 20 \mathrm{BN}$ có di căn phổi 1 nốt đơn độc.

-21/25 nốt di căn năm ở thùy dưới. 04/25 nằm thùy trên và giữa.

- DKTB tổn thương $14,5 \pm 5,9 \mathrm{~mm}$ (từ 6$30 \mathrm{~mm}$ ). $8 / 25$ nốt có $\mathrm{KT}$ dưới $10 \mathrm{~mm}$. 14/25 nốt $10-20 \mathrm{~mm}$ và $3 / 25$ nốt $20-30 \mathrm{~mm}$

Bảng 1. Kích thước và thời gian đốt nôt di căn phổi

\begin{tabular}{|c|c|c|}
\hline $\begin{array}{c}\text { DKTB nốt di } \\
\text { căn }\end{array}$ & Số lượng & $\begin{array}{c}\text { Thời gian đốt } \\
\text { (phút) }\end{array}$ \\
\hline$<10 \mathrm{~mm}$ & $8 / 25$ & $6,5 \pm 1,77$ \\
\hline $10-20 \mathrm{~mm}$ & $14 / 25$ & $8,5 \pm 2,7$ \\
\hline $20-30 \mathrm{~mm}$ & $3 / 25$ & $14 \pm 1,5$ \\
\hline
\end{tabular}

- 24/25 nốt đốt 1 lần và có 01 nốt phải thực hiện đốt lần 2.

Trong đó có 23 nốt di căn đáp ứng hoàn toàn sau theo dõi 1, 3 tháng. 01 nốt đáp ứng không hoàn toàn (còn phần ngấm thuốc sau tiêm trên CLVT) đã được đốt lại lần 2, kiểm tra sau 3 tháng hoại tử hoàn toàn. 01 nốt được xếp loại bệnh tiến triển do không hoại tử hoàn toàn và xuất hiện tổn thương mới nên không tiếp tục điều trị.

Bảng 2: Phân loại mức độ hoại tử theo MRECIST

\begin{tabular}{|c|c|c|c|c|}
\hline \multirow{2}{*}{$\begin{array}{c}\text { Đáp ứng của } \\
\text { mRECIST }\end{array}$} & \multicolumn{2}{|c|}{$\begin{array}{c}\mathbf{1} \text { tháng } \\
\mathbf{N = 2 5}\end{array}$} & \multicolumn{2}{c|}{$\begin{array}{c}\mathbf{3} \text { tháng } \\
\mathbf{N = 2 5}\end{array}$} \\
\cline { 2 - 5 } & $\mathbf{N}$ & $\mathbf{\%}$ & $\mathbf{n}$ & $\mathbf{\%}$ \\
\hline Đáp ứng hoàn toàn & 23 & $92 \%$ & 24 & $96 \%$ \\
(CR) & & $4 \%$ & 0 & 0 \\
\hline Không hoàn toàn(PR) & 1 & $4 \%$ & 0 & 0 \\
\hline Bệnh ốn định (SD) & 0 & 0 & 0 & 0 \\
\hline Bệnh tiến triển (PD) & 1 & $4 \%$ & 1 & $4 \%$ \\
\hline
\end{tabular}

Trong nghiên cứu của chúng tôi đánh giá hiệu quả điều trị bằng chụp CLVT có tiêm thuốc đối quang sau 1, 3 tháng. Sau 1 tháng có 23 tổn thương (92\%) hoại tử hoàn toàn, $01 \mathrm{BN}$ hoại tử không hoàn toàn được điêuu trị DNSCT lần 2 và 01 BN thuộc bệnh tiến triển. Sau 3 tháng có 24 nốt tổn thương $(96 \%)$ hoại tử hoàn toàn và 01 nốt thuộc bênh tiến triển.

Các tai biến và biến chứng sau quá trình điêu trị: Sốt: 18 (69\%): có 4 BN sốt nhẹ, 9 BN sốt vừa và $5 \mathrm{BN}$ sốt cao tuy nhiên các trường hợp sốt chỉ cần dùng thuốc hạ sốt.

Đau ngực 19 BN (73\%), (đau ít và vừa chiếm $15 \mathrm{BN}$ và đau nhiều là $4 \mathrm{BN}$ các trường hợp này chỉ cần theo dõi và dùng thuốc giảm đau

Khó thở 4 BN $(15,4 \%)$, khó thở nhe và vừa đáp ứng với điều trị nội khoa, không cần can thiệp.

Tràn khí $03 \mathrm{BN}(11 \%)$ và tràn máu màng phổi $01 \mathrm{BN}(3.8 \%)$ với số lượng ít không cần can thiệp.

Ho máu 03 BN $(11 \%)$ các trường hợp đều là ho máu ít và huyết động ổn định, không cần truyền máu.

Viêm thành ngực $01 \mathrm{BN}(3,8 \%) \mathrm{BN}$ cần sát trùng và thay băng hàng ngày.

Không có trường hợp nào tử vong trong thời gian theo dõi 90 ngày.

Liên quan triệu chứng sốt, đau ngực, tràn khí, ho máu tăng theo kích thước của nốt di căn nhưng khác biệt không có ý nghĩa thống kê (với $P>0,05)$.

Tràn máu màng phổi cũng tăng theo kích thước nốt di căn, sự khác biệt có ý nghĩa thống kê (với $\mathrm{P}=0,019$ ).

\section{BÀN LUẬN}

DNSCT là phương pháp được lựa chọ điều trị nốt di căn phổi từ lâu và dần trở lên phổ biến tại nhiều nước trên thế giới. Nhóm nghiên cứu của chúng tôi gồm 20 bệnh nhân với 25 nốt tổn thương di căn phổi đường kính các nốt $\leq 30 \mathrm{~mm}$.

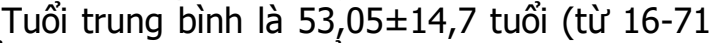
tuổi). Đây cũng là độ tuổi gặp trong các NC khác 1,2 . Ung thư hay gặp tuổi trên 40 , nhiêu nhất $50-$ 60 tuổi. Tỷ lệ mắc ung thư càng cao thì tỷ lệ thuận với tổn thương di căn tới phổi.

Trong $\mathrm{NC}$ có $9 \mathrm{BN}$ nam (45\%) và $11 \mathrm{BN}$ nữ (55\%), tỷ lệ nam/nữ là 0,82:1. Theo NC của Meybaun và cộng sự (2014) có tỷ lệ nam/nữ là 1,06:1 ${ }^{1}$. Theo NC Tongdee (2013) có tỷ lệ nam: nữ là $2,5: 1^{2}$. Như vậy có sứ khác biệt giữa NC của chúng tôi và Tongdee có thể giải thích do số lượng bệnh nhân chưa nhiều và mô hình điều trị các bệnh ung thư tại bệnh viện Việt Đức.

DKTB nốt di căn phổi là $14,5 \pm 5,9 \mathrm{~mm}$ (từ 6$30 \mathrm{~mm}$ ) tương đồng với NC của Clara Prud (2019) $14 \pm 0,7 \mathrm{~mm}(<30 \mathrm{~mm})^{3} 2$. Các nghiên cứu điêuu trị đều tập trung và các tổn thương có đường kính 
nhỏ hơn $30 \mathrm{~mm}$, vì hiện nay khả năng diện đốt đat hiệu quả tốt với các tổn thương này, khi các tổn thương có kích thước lớn hơn khó đạt hiệu quả hoai tử hoàn toàn.

Thời gian đốt trung bình trong NC là $9,1 \pm 2,8$ phút, thời gian đốt u< $10 \mathrm{~mm}$ là: $6.5 \pm 1,77$ phút, $10-20 \mathrm{~mm}$ là: $5,5 \pm 2,7$ phút và $20-30 \mathrm{~mm}$ là $14 \pm 1,5$ phút. Theo nghiên cứu của Thomas Schneider và cộng sự (2007), nốt $\mathrm{KT}<10 \mathrm{~mm}$, thời gian đốt tối đa là 10 phút và $10 \mathrm{~mm}<\mathrm{KT}<$ $25 \mathrm{~mm}$, thời gian đốt tối đa là 15 phút ${ }^{4}$. Như vậy thời gian đốt không có sự khác biệt với các nguyên cứu khác. Tuy nhiên, thời gian đốt phụ thuộc vào hình thái, kích thước và khả năng tiếp cận u nên các nốt có DKTB giống nhau nhưng có thể thời gian đốt là khác nhau.

Trong NC của chúng tôi: sau 1 tháng có $23 / 25$ nốt $(92 \%)$ đáp ứng hoại tử hoàn toàn, 01 BN $(4 \%)$ đáp ứng không hoàn toàn và 01 nốt (4\%) thuộc bệnh tiến triển. Sau 3 tháng: có $24 / 25$ nốt hoại tử hoàn toàn chiếm $(96 \%)$ và 01 nốt $(4 \%)$ thuộc bệnh tiến triển. Theo NC của Chua và cộng sự 2010 với 148 BN được điều trị: 66 bệnh nhân $(46 \%)$ đáp ứng hoàn toàn, 38 bệnh nhân $(26 \%)$ đáp ứng một phần, 57 bệnh nhân (39\%) bệnh ổn định và 23 bệnh nhân (16\%) bệnh tiến triển. Theo NC Tongdee (20072013), 14BN với 27 nốt di căn được điều trị RFA tỷ lệ hoại tử hoàn toàn không tái phát $81 \%$, tỷ lệ tái phát cục bộ là $19 \%$. Như vậy trong NC của chúng tôi tỷ lệ đáp ứng hoàn toàn cao hơn các NC khác, điêu này có thể giải thích do cõ̃ mẫu nhỏ, thời gian NC ngắn, kích thước nhỏ $(<30 \mathrm{~mm})$ và quan trọng hơn hết do ứng dụng phần mềm Fluoroscopy giúp định vị chính xác vị trí kim vào nốt tổn thương, đặc biệt là các nốt tổn thương nhỏ hơn $10 \mathrm{~mm}$.
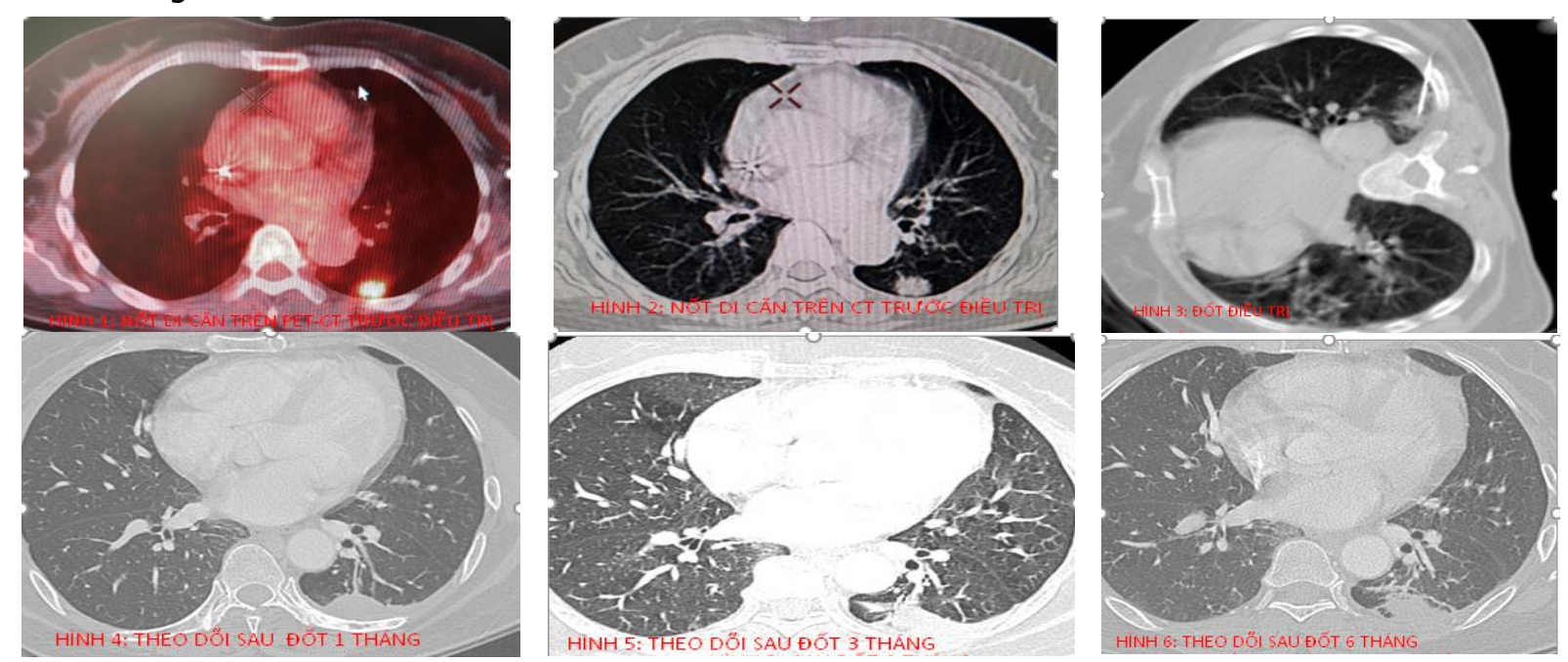

Biến chứng sau thủ thuật, gặp nhiều nhất là sốt và đau ngực với tỷ lệ là $69 \%$ và $73 \%$, các biến chứng khác gặp với tỷ lệ thấp là khó thở $15,5 \%$, tràn khí và ho máu $11 \%$, tràn máu và viêm thành ngực là $3,8 \%$. Các biến chứng đều ở mức độ nhẹ, không cần điều trị đặc biệt Theo NC của Chua và cộng sự (2010) ${ }^{5}$ với 60 BN có 125 nốt di căn phối tỷ lệ biến chứng là $45 \%$ tràn khí màng phổi, trong đó $30 \%$ phải hút liên tục, $11 \%$ có tràn máu màng phổi, $8 \%$ đau ngực. theo NC của De baer $(2015)^{6}$ với $566 \mathrm{BN}$ tỷ lể tràn khí là $67 \%, 28 \%$ mức độ nhe không cần điều trị gì đặc biệt, $14 \%$ mức độ nhe chọc hút khí bằng kim nhỏ và $58 \%$ BN phải dẩn lưu màng phổi hút liên tục. Nghiên cứu của chúng tôi tỷ lệ tràn khí là $11 \%$ thấp hơn nhiều so với 2 NC trên có thể giải thích do các nốt nằm ở ngoại vi cách xa mạch máu lớn và thời gian kim chọc tiếp cận tổn thương ngắn nhờ ứng dụng phần mềm Fluoroscopy. Tỷ lệ BN sốt, đau ngực ở mức độ nhe nhưng cao hớn các NC khác. Trong NC của chúng tôi có 01 trường hợp với nốt di căn nằm sát thành ngực, quá trình đốt đường gây viêm thành ngực. 3 BN có biến chứng ho máu được điều trị nội khoa cầm máu, không có trường hợp nào cần can thiệp ngoại khoa. Không có $\mathrm{BN}$ tử vong trong quá trình theo dõi sau điều trị 90 ngày.

Ca lâm sàng: BN nữ 55 tuổi tiền sử ung thư đại tràng đã phẫu thuật cách 3 năm, theo dõi thường xuyên, phát hiện nốt di căn đơn độc thùy dưới phổi bên trái đã được sinh thiết khẳng định chẩn đoán, BN được chụp PET-CT xác định tổn thương và khẳng định không có di căn ở vị trí khác, đáp ứng điêu kiện điều trị bằng phương pháp DNSCT. 


\section{KẾT LUẬN}

Đốt nhiệt sóng cao tần là phương pháp an toàn và hiệu quả trong điều nốt di căn phổi đường kính nhỏ hơn $3 \mathrm{~cm}$ với tỷ lệ loại bỏ hoàn toàn tổn thương cao và tỷ lệ biến chứng thấp.

\section{TÀI LIÊU THAM KHẢO}

1. Meybaum, C.; Graff, M.; Fallenberg, E. M.; Leschber, G.; Wormanns, D. Contribution of CAD to the Sensitivity for Detecting Lung Metastases on Thin-Section CT - A Prospective Study with Surgical and Histopathological Correlation. Rofo 2020, 192 (1), 65-73. https://doi.org/10.1055/a-0977-3453.

2. Tongdee, T.; Tantigate, P.; Tongdee, $\mathbf{R}$. Radiofrequency Ablation of Lung Metastasis Not Suitable for Surgery: Experience in Siriraj Hospital. J Med Assoc Thai 2015, 98 (10), 1019-1027.

3. Prud'homme, C.; Deschamps, F.; Moulin, B.; Hakime, A.; Al-Ahmar, M.; Moalla, S.; Roux, C.; Terititehau, C.; de Baere, T.; Tselikas, L. Image-Guided Lung Metastasis Ablation: A Literature Review. Int J Hyperthermia 2019, 36 (2), 37-45. https://doi.org/ 10.1080/ 02656736.2019 .1647358$.

4. Schneider, T.; Warth, A.; Herpel, E.; Schnabel,
P. A.; von Deimling, A.; Eberhardt, R.; Herth, F. J. F.; Dienemann, H.; Hoffmann, $H$. Intraoperative Radiofrequency Ablation of Lung Metastases and Histologic Evaluation. The Annals of Thoracic Surgery 2009, 87 (2), 379-384. https://doi.org/10.1016/j.athoracsur.2008.10.088.

5. Chua, T. C.; Sarkar, A.; Saxena, A.; Glenn, D.; Zhao, J.; Morris, D. L. Long -Term Outcome of Image-Guided Percutaneous Radiofrequency Ablation of Lung Metastases: An Open-Labeled Prospective Trial of 148 Patients. Annals of Oncology 2010, 21 (10), 2017-2022. https://doi.org/10.1093/annonc/mdq098.

6. Baère, T. de; Aupérin, A.; Deschamps, F.; Chevallier, P.; Gaubert, Y.; Boige, V.; Fonck, M.; Escudier, B.; Palussiére, J. Radiofrequency Ablation Is a Valid Treatment Option for Lung Metastases: Experience in 566 Patients with 1037 Metastases. Annals of Oncology 2015, 26 (5), 987-991. https://doi.org/10.1093/annonc/mdv037.

7. Pfannschmidt, J.; Bischoff, M.; Muley, T.; Kunz, J.; Zamecnik, P.; Schnabel, P. A.; Hoffmann, H.; Dienemann, H.; Heussel, C. P. Diagnosis of Pulmonary Metastases with Helical CT: The Effect of Imaging Techniques. Thorac Cardiovasc Surg 2008, 56 (8), 471-475. https://doi.org/10.1055/s-2008-1038887.

\title{
ĐĂC ĐIỂM LÂM SÀNG, HÌNH ẢNH CộNG HƯởNG TỪ NÃO MẠCH NÃO VÀ BƯớC ĐÂUU ĐÁNH GIÁ HIỀU QUẢ CỦA RIVAROXABAN TRONG ĐIỀU TRI HUYẾT KHỐI TĨNH MACH NÃO
}

\author{
Phạm Thị Ngọc Linh ${ }^{1}$, Võ Hồng Khôi ${ }^{2}$, Nguyễn Ngọc Hòa ${ }^{3}$
}

\section{TÓM TẮT}

Muc tiêu: Mô tả đăc điểm lâm sàng, hình ảnh cộng hưởng từ não mạch não và bước đâuu đánh giá hiệu quả của Rivaroxaban trong điều trị huyết khối tĩnh mach não. Đối tượng và phương pháp: Nghiên cứu mổ tả tiến cứu được thực hiện trên 38 bệnh nhân huyết khối tĩnh mach não điều tri tai Khoa Thần Kinh, Bệnh viện Bạch Mai từ tháng 3 nằm 2020 đến tháng 6 nắm 2021. Kết quả: Tuổi trung bình của nhóm nghiên cứu là $42,4 \pm 14,8$. Tỷ lệ nam/nữ là 1,2 . Thời gian khởi phát: cấp tính có 6 bênh nhân $(15,8 \%)$, bán cấp có 31 bệnh nhân $(81,6 \%)$, mạn tính có 1 bệnh nhân $(2,6 \%)$. Triệu chứng thường gặp nhất là đau đầu $(94,7 \%)$, tiếp theo là liệt nửa người $(34,2 \%)$ và co giât $(28,9 \%)$. Trên phim công hưởng từ não mach não,tổn thương hay gặp nhất là nhồi máu não $(31,6 \%)$, chảy máu não $(21,1 \%)$ và nhồi máu não

${ }^{1}$ Trường Đại học Y Hà Nội

${ }^{2}$ Bênh viên Bach Mai

${ }^{3}$ Bềnh viền Hưư nghi Đa khoa Nghê An.

Chịu trách nhiêm chính: Phạm Thị Ngọc Linh

Email: Ngoclinhpham181295@gmail.com

Ngày nhận bài: 17.6.2021

Ngày phản biên khoa họ: 16.8.2021

Ngày duyệt bài: 23.8.2021 chuyển dang chảy máu $(18,4 \%)$. Vị trí huyết khối thướng gắp nhất là xoang dọc trên $(73,7 \%)$, xoang ngang $(63,2 \%)$ và xoang sigma $(47,4 \%)$. Bước đầu đánh giá hiêu quả của Rivaroxaban trong điều tri huyết khối tĩnh mạch não sau 12 tuân theo dõi điêu trị khá khả quan. Tỷ lệ bênh nhân hồi phuc tốt có điểm mRS từ 0-1 điểm 94,7\%. Tỷ lệ tái phát các sự kiện huyết khối tĩnh mach thấp 2,6\%.

Từ khoá: Huyết khối tĩnh mạch não, rivaroxaban.

\section{SUMMARY}

\section{CLINICAL FEATURES CLINICAL FEATURES MAGNETIC RESONANCE IMAGING AND INITIAL \\ EVALUATION OF THE EFFECTIVENESS OF RIVAROXABAN IN THE TREATMENT OF CEREBRAL VENOUSTHROMBOSIS}

Objective:To describe clinical features, magnetic resonance imaging and initial evaluate the effectiveness of rivaroxaban in the treatment of cerebral venous thrombosis. Subjects and methods: A prospective, descriptive study of 38 patients with cerebral venous thrombosistreated at the Department of Neurology, Bach Mai Hospital from March 2020 to June 2021. Results: Mean age was $42.4 \pm 14.8$, male/female ratio was 1.2:1. Acute onset was seen in 6 patients $(15.8 \%)$, subacute in $31(81.6 \%)$ and 